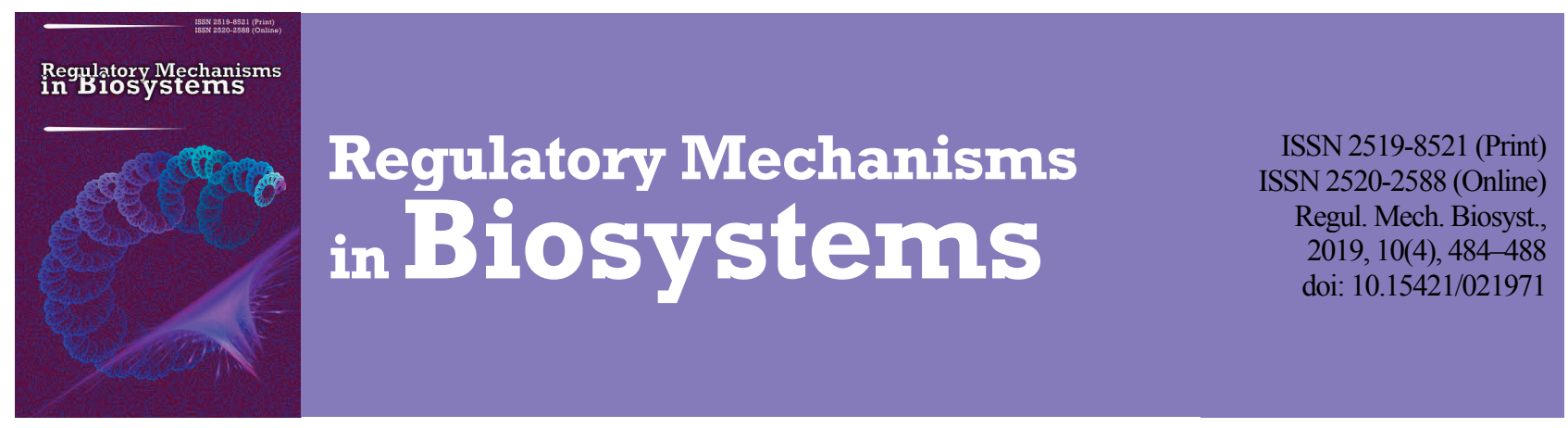

\title{
Evaluation of antimicrobial properties of polymer nanocomposites for medical application
}

\author{
O. V. Hopta*, M. M. Mishyna*, A. O. Syrova*, V. O. Makarov*, V. L. Avramenko**, D. O. Mishurov** \\ *Kharkiv National Medical University, Kharkiv, Ukraine \\ **National Technical University "Kharkiv Polytechnic Institute", Kharkiv,Ukraine
}

Article info

Received 16.10.2019

Received in revised form 13.11.2019

Accepted 14.11.2019

Hopta, O. V., Mishyna, M. M., Syrova, A. O., Makarov, V. O., Avramenko, V. L., \& Mishurov, D. O. (2019). Evaluation of antimicrobial properties of polymer nanocomposites for medical application. Regulatory Mechanisms in Biosystems, 10(4), 484-488. doi:10.15421/021971

Kharkiv National Medical University, Nauky Av.,4 Kharkiv, 61022,Ukraine. Tel: $+38-057-707-73-80$ E-mail:

meduniver@knmu.kharkov.ua

The paper is devoted to the investigation of antimicrobial activity of polymer nanocomposites of both low-density polyethylene and nonwoven polymeric material (a mixture of woven and polyester fibers) that had been impregnated by $\mathrm{Cu}$ nanoparticles. The microorganisms were grown according to generally accepted microbiological rules and on media recommended for each bacteria family. Formation of biofilms of microorganisms was studied on the surface of microtiter plates for enzyme-linked immunosorbent assay. After incubation of microtiter plates, the culture medium was removed from the wells. The wells were rinsed five times with sterile distilled water. The plates were air dried for 45 minutes and each well was stained with $1 \%$ crystal violet solution in water for $45 \mathrm{~min}$. After staining, the plates were washed with sterile distilled water five times. The quantitative analysis of biofilm production was done by adding $95 \%$ ethanol for discoloration of the wells. The research shows the antibacterial activity of $\mathrm{Cu}$ nanoparticles on planktonic forms of the investigated microorganisms, which prevented the formation of dense biofilms. With the use of low-density polyethylene impregnated by $\mathrm{Cu}$ the ability to form biofilms by planktonic cells of the referent strains of microorganisms was detected to decrease by 1.7 (Escherichia coli), 12.3 (Klebsiella pneumonia) times in the studied strains and with the use of nonwoven polymeric material treated by $\mathrm{Cu}$ nanoparticles, the ability to form biofilms decreased by 1.8 (Escherichia coli) - 21.8 (Klebsiella pneumonia) times in the studied strains. In subjecting the formed daily biofilms of referent strains of microorganisms to $\mathrm{Cu}$ nanoparticles, the destruction of biofilms of the studied strains of microorganism was observed as well as violation of the integrity of the biofilm monolayer and decrease of density index in comparison with control values. As a result, the obtained polymer nanocomposites can be recommended for preventive use in the fight against nosocomial infections. The practical relevance of this study lies in the possibility of reducing the incidence of purulent-inflammatory diseases and mycoses and, accordingly, reduction of the costs of treating these diseases.

Keywords: microbial biofilms; Cu nanoparticles; low-density polyethylene; non-woven polymeric material.

\section{Introduction}

Recently, use of polymer materials in various areas has grown rapidly. The development of such areas as aviation, engineering, transport, the building and the food industry is impossible without the use of polymer materials (Koniuszewska \& Kaczmar, 2016; Ghori et al., 2018; Gutiérrez, 2018). Polymers play a particularly an important role in modern medicine. In this area, polymers are used widely, for example in the medicotechnical sphere in reconstructive surgery, traumatology, orthopedics, ophthalmology, stomatology, maxillofacial surgery, and in functional nodes of surgical devices, etc. (Babker et al., 2018; Rokaya et al., 2018).

Numerous studies have been conducted on the exploitation of properties of polymer materials subject to different types of destruction, such as thermal, thermo-oxidative, radiation, mechanical, photochemical and other. However, microbiological destruction i.e. the destruction of polymer materials under the influence of various microorganisms has only been systematically studied in recent years. Besides, it is well-known that microbiological destruction is one of the most dangerous types of destruction that affects polymer materials and causes failure of technical systems. It is also known that the main factor of pathogenicity of microorganisms is biofilm formation (Pathak \& Navneet, 2017; Devi et al., 2015). About $99 \%$ of microorganisms can form biofilms. Due to this property, pathogenic fungi and bacteria are able to survive in adverse conditions, are resistant to disinfectants and cause infectious processes. Recent studies indicate that bacteria are capable of acquiring signs of virulence in biofilms, in contrast to single bacteria. A dangerous feature of infections caused by biofilm-forming microorganisms is their high resistance to antibiotics (Tasneem et al., 2018). Many chronic and purulent-inflammatory diseases are the consequence of nosocomial infection as a result of the use of medical devices (central venous catheters, urinary catheters, prosthesis, mechanical heart valves etc.) on the surface of which microorganisms form biofilms. The development of new methods to combat biofilms is still an urgent issue today (Krishnan, 2015).

Thus, the study of microbiological destruction of polymer materials is relevant, because it could lead to possible development of new methods of protecting these materials (Pekhtasheva et al., 2012; Palza, 2015).

Based on the above, of particular note are non-woven polymer composites based on a polymer matrix filled with metal nanoparticles (such as $\mathrm{Cu}, \mathrm{Ag}$ ) for medical applications (Deng et al., 2015). It is known that nanoparticles reveal new features due to quantum-size effects and, consequently, reactivity and biological activity growth (Khezerlou et al., 2018). In previous works (Borkow et al., 2009; Ahire et al., 2016; Khan \& Yaqoob, 2017) the positive effect of nanoparticles of such metals as $\mathrm{Cu}$ in connection with bactericidal properties was considered. Disinfectant properties of $\mathrm{Cu}$ alloys surfaces were determined but $\mathrm{Cu}$ antibacterial activity mechanisms, its antimicrobial properties and ability to impact microbial 
biofilm formation (Agarwala et al., 2014; Jamal et al., 2018) are still not systematically understood and are only covered in scattered studies. Nano$\mathrm{Cu}$ has a number of advantages over other nanoparticles: first of all, bioavailability in the human body, second, sufficient antimicrobial effectiveness, third, efficiency in production. Cu bioavailability with the human organism is explained by the fact that this metal is a component of a great amount of vital enzymes such as lysyl oxidase, $\mathrm{Cu}-\mathrm{Zn}$-superoxide dismutase, tyrosinase, ceruloplasmin, cytochrome oxidase, etc. Analysis of existing studies has shown the relevance of the issue of studying copper nanoparticles, which have an antimicrobial effect due to displacement of essential metals from their native binding sites or through ligand interactions, and also contribute to the formation of highly reactive hydroxyl radicals as a result of reactions (Gaetke et al., 2014).

Thus, the purpose of this investigation is the determination of the influence of $\mathrm{Cu}$ nanoparticles incorporated into polymer matrices based both on low density poly(ethylene) and non-woven polymer composite (mixture of woven fibers/polyethylene teraphthalate (PET) fibers) on formation of microbial biofilms which could lead to purulentinflammatory processes in the human organism.

\section{Material and methods}

As polymer matrices we used a commercial-grade low-density poly(ethylene) (LDPE, 18103-035, Ukraine) with a melt index of $2.0 \mathrm{~g} / 10 \mathrm{~min}$ $\left(2.16 \mathrm{~kg} / 190{ }^{\circ} \mathrm{C}\right)$ and commercial-grade non-woven polymer material (a mixture of woven fibers/polyethylene terephthalate (PET) fibers, StelTicks, Ukraine). Water dispersion of avalent $\mathrm{Cu}$ nanoparticles (CuNP) of spherical form with average size, consequently, $20 \mathrm{~nm}(20.2 \pm 4.5 \mathrm{~nm})$ was synthesized by chemical condensation in the water environment in the way of copper sulfate recovery by sodium borohydride. Final concentrations of precursors in conjugate: $\mathrm{CuNP}-3.2 \mathrm{mg} / \mathrm{mL}$ per metal.

For the correct interpretation of the processes associated with the release of $\mathrm{Cu}$ nanoparticles from polymer-copper nanocomposites, first, pure ones were analyzed. Figure 1 shows an electron-microscopic photograph of obtained avalent $\mathrm{Cu}$ nanoparticles.

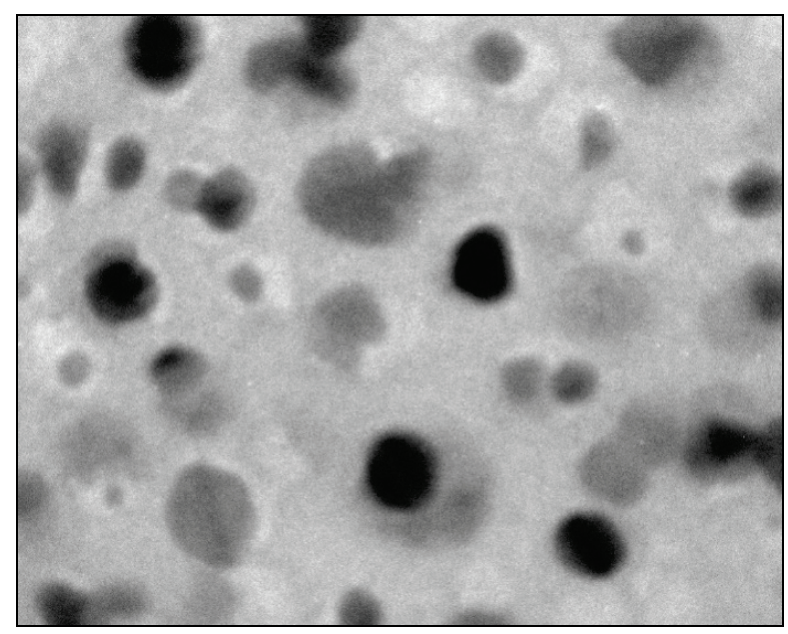

Fig. 1. Electron-microscopic photograph of avalent

$\mathrm{Cu}$ nanoparticles: water dispersion of avalent $\mathrm{Cu}$ nanoparticles of spherical form with average size $20 \mathrm{~nm}(20.2 \pm 4.5 \mathrm{~nm})$

Final concentrations of precursors in conjugate: $\mathrm{CuNP}-3.2 \mathrm{mg} / \mathrm{mL}$ per metal. Size distribution charts (Fig. 2) were received in the way of transmission electron microphotograph analysis with the help of Pebbles and Pebble Juggler programs according to the requirements of the standard ISO 13322-1:2014 (Simonov, 2016).

Calculations were produced with the use of at least three microphotographs of each substance. Representativeness of image sets is confirmed by absence of statistically valid differences (single factor dispersive analysis ANOVA) between the results of the calculation of the parameter under study according to separate photos. General number of particles for the size distribution chart building comprised at least 1000 units.

To confirm of the purity of $\mathrm{Cu}$ nanoparticles, radiostructural microanalysis was carried out. The results showed that content of $\mathrm{Cu}$ as share of nanoparticles is $100 \%$ (Fig. 3). Presence of oxygen in particle structure was not recorded. Besides, copper oxide and hydroxide were not found in the chemical composition microanalysis. It proves that the nanostructures were particles of avalent $\mathrm{Cu}$. Trace amounts of other chemical elements found during the analysis were not compounds of the sample under study and belonged to microscope lining material.

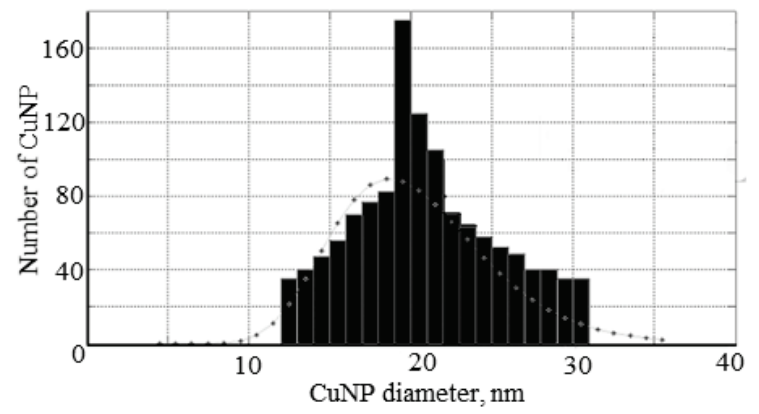

Fig. 2. Size distribution of avalent $\mathrm{Cu}$ nanoparticles according to the data of Pebbles and Pebble Juggler programs: diameter (nm) average 20.2; the median 19.9; standard deviation 4.5 (22.4\%); nanoparticles 1015

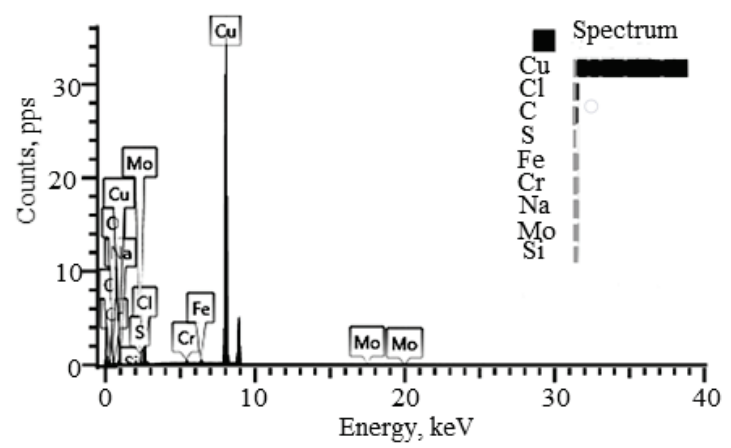

Fig. 3. Radiostructural microanalysis of CuNP chemical composition: content of $\mathrm{Cu}$ as part of nanoparticles is $100 \%$; on the abscissa axis: magnitude of theparticle energy in $\mathrm{keV}$; on the ordinate axis:

fraction of pulses per second (pps) and energy $(\mathrm{eV})$

The following reference strains of the microorganisms: Candida albicans CCM 885, Escherichia coli ATCC $25922($ F50) $=$ NCDC F 50, Klebsiella pneumonia NCTC 5055 = SS B 5055, Pseudomonas aeruginosa ATCC 27853 = NCDCF-51, Staphylococcus aureus ATCC $25923=$ NCDC $25923=$ F-49, Streptococcus pyogenes 130001 were the studied objects.

Two series of samples were prepared. The first series of the samples (LDPE/CuNP) was prepared in the form of string (diameter $1.8 \mathrm{~mm}$ ). The string samples were received by mixing $\mathrm{Cu}$ nanoparticles $(1 \mathrm{wt} \%)$ with LDPE granules, which has been approved for medical use. Then the strings from the mixture were produced with specially designed melt index apparatus IIRT-AM-1 device at the temperature $190^{\circ} \mathrm{C}$ and $2.16 \mathrm{~kg}$ loading (standard conditions for LDPE). Then, the strings were cooled on air, packed in polyethylene packages, and passed on for microbiological study. The samples of the nanocomposites from non-woven polymer/ CuNP were prepared in two steps. In the first step, the samples of commercial-grade nonwoven polymer composites were prepared by cutting from billets. In the second step, the received samples were soaked in water suspension of $\mathrm{Cu}$ nanoparticles at a concentration of $0.068 \%$ at room temperature for $72 \mathrm{~h}$. Then, the obtained samples were taken out from the suspension and dried at $90-105^{\circ} \mathrm{C}$ for $2-4 \mathrm{~h}$.

The melt index of the LDPE was determined by apparatus IIRT-AM-1 device. Average size of $\mathrm{Cu}$ nanoparticles was determined with radiostructural microanalysis by energy dispersion spectroscopy (IETEM 250 energy dispersion spectrometer with X-Max 80 detector, Oxford Instruments Analytical, for JEM-1230, JEOL LTD transmission electronic microscope). Size distribution charts were received in the way of transmission electron microphotograph analysis with the help of Pebbles and Pebble Juggler programs according to the requirements of the standard ISO 13322- 
1:2014. A Spectrophotometer "Thermo Scientific Multiskan EX 355" microplate reader for determining the concentration of microbial cells was used. For determining the turbidity of the suspension of microbial cells the apparatus Densi-La-Meter (PLIVA-Lachema a. s., Czech) was used.

The kinetics study of researched microbes under influence of the samples: cultures grown on solid nutrient medium were washed out by suspension medium and their concentration was brought up to corresponding units according to McFarland scale, with the help of a DensiLa-Meter device. Microorganisms were grown up at $\mathrm{T}=37^{\circ} \mathrm{C}$, concentration of microbial cells was determined with the help of microplate reader "Multiskan EX 355" (wavelength $540 \mathrm{~nm}$ ). Synchronization of periodic culture was done by selection (Mitchison and Vincent method). Synchronization of periodic cultures of the investigated strains was carried out after kinetic growth of asynchronic culture determination. Formation of microorganism biofilms was studied with the help of investigation of the bacterial strain's ability to adhere to the surface of microtiter plates for enzyme-linked immunosorbent assay (O'Toole et al., 2000; Murthy et al., 2011).

Strains were grown up according to common microbiological methods on media and in conditions of culturing recommended for each bacteria family. The received bacterial suspension of the necessary concentration was inoculated into the well of the microtiter plates with further incubation according to the conditions for each bacteria family in wet containers under the closed tablet lid. Quantitative expressions of biofilm formation degree were the values of optical density, measured on spectrophotometer at $540 \mathrm{~nm}$ according to patent No UA $47944 \mathrm{U}$ (Mishina et al., 2019). When processing the results the statistical program Statistica 9.0 (StatSoft Inc., USA) was used.

\section{Results}

The result of the study of the antibacterial effect of $\mathrm{Cu}$ nanoparticles which were applied to strings and non-woven polymer material on ability of microorganism test-strains to form biofilms and on daily biofilms showed that the ability to form biofilms with planktonic cells of referent-strains of microorganisms with the use of $\mathrm{Cu}$ impregnated strings decreased 1.7 times in the researched $E$. coli strains, 12.3 times in $K$. pneumonia strains, 7.2 times in $P$. aeruginosa strains, 6.3 times in S. aureus strains, 6.9 times in $S$. pyogenes strains and 5.2 times in C. albicans strains. The ability to form biofilms with planktonic cells of referent-strains of microorganisms with the use of $\mathrm{Cu}$ impregnated nonwoven polymer material treated by $\mathrm{Cu}$ nanoparticles decreased 1.8 times in the researched $E$. coli strains, 21.8 times in K. pneumonia stains, 8.3 times for $P$. aeruginosa and $S$. aureus strains, 9.0 times in $S$. pyogenes strains and 6.6 times in $C$. albicans strains in comparison with control values. The difference is statistically significant between control and experimental nanocomposites $-\mathrm{P}<0.001$ (Fig. 4, Table 1,2).

\section{Table 1}

Impact of $\mathrm{Cu}$ nanoparticles on the ability

to form biofilms with microbial planktonic cells

\begin{tabular}{lccc}
\hline \multicolumn{1}{c}{ Microorganism strains } & $\begin{array}{c}\text { Non-woven } \\
\text { polymer material/ } \\
\text { CuNP, OD }\end{array}$ & $\begin{array}{c}\text { LDPE/CuNP, } \\
\text { OD }\end{array}$ & $\begin{array}{c}\text { Control, } \\
\text { OD }\end{array}$ \\
\hline $\begin{array}{l}\text { E. coli ATCC 25922 (F50) } \\
\text { NCDC F 50 }\end{array}$ & $0.86 \pm 0.016^{* * *}$ & $0.93 \pm 0.024 * * *$ & $1.56 \pm 0.02$ \\
$\begin{array}{l}\text { K. pneumonia } \text { NCTC } \\
\text { 5055=SS B 5055 }\end{array}$ & $0.09 \pm 0.019 * * *$ & $0.16 \pm 0.016^{* * *}$ & $1.96 \pm 0.017$ \\
$\begin{array}{l}\text { P. aeruginosa ATCC } \\
\text { 27853= NCDCF-51 }\end{array}$ & $0.26 \pm 0.031^{* * *}$ & $0.35 \pm 0.023^{* * *}$ & $2.16 \pm 0.023$ \\
$\begin{array}{l}\text { S. aureus ATCC 25923 } \\
\text { NCDC 25923 = F-49 }\end{array}$ & $0.32 \pm 0.027^{* * *}$ & $0.42 \pm 0.018^{* * *}$ & $2.64 \pm 0.016$ \\
$\begin{array}{l}\text { S. pyogenes 130001 } \\
\text { C. albicans CCM } 885\end{array}$ & $0.26 \pm 0.026^{* * *}$ & $0.34 \pm 0.016^{* * *}$ & $2.33 \pm 0.018$ \\
\hline
\end{tabular}

Note: LDPE - low-density poly(ethylene); CuNP - copper nanoparticles; DO optical density; $\mathrm{x} \pm \mathrm{SD}, \mathrm{n}=6$; the differences are significant between control and experimental nanocomposites $* * *-\mathrm{P}<0.001$.

Assessing the results received after determination of action of $\mathrm{Cu}$ nanoparticles on formed daily biofilms of referent strains of microorganisms showed the destruction of biofilms of the studied strains of micro486 organisms as well as violation of the integrity of the biofilm monolayer and density reduction: in using strings treated by $\mathrm{Cu}$ nanoparticles by 1.6 times in $P$. aeruginosa strains, 1.7 times in $S$. pyogenes and $E$. coli strains, 1.8 times in S. aureus strains and 1.9 times in K. pneumonia and C. albicans strains.

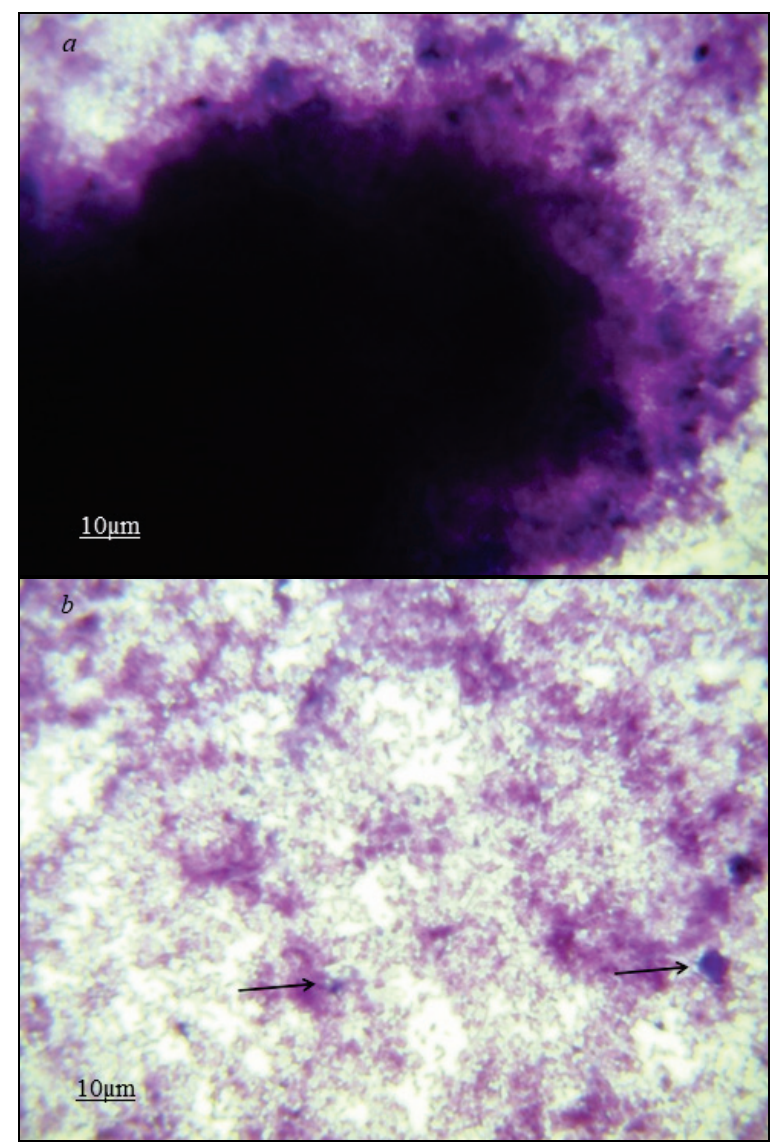

Fig. 4. Klebsiella pneumonia biofilm formation: $a-$ control; $b$ - CuNP action; two sets of SEM images

Table 2

The decrease of daily biofilm formation

with planktonic cells of microorganism referent-strains

\begin{tabular}{lcc}
\hline \multicolumn{1}{c}{ Microorganism strains } & $\begin{array}{c}\text { LDPE/CuNP, } \\
\text { times }\end{array}$ & $\begin{array}{c}\text { Non-woven polymer } \\
\text { material/CuNP, times }\end{array}$ \\
\hline E. coli ATCC 25922 (F50) & 1.7 & 1.8 \\
= NCDC F 50 & 12.3 & 21.8 \\
K. pneumonia NCTC 5055=SS B 5055 & 7.2 & 8.3 \\
P. aeruginosa ATCC 27853 & & \\
= NCDCF-51 & 6.3 & 8.3 \\
S. aureus ATCC 25923 & 6.9 & 9.0 \\
= NCDC 25923 = F-49 & 5.2 & 6.6 \\
S. pyogenes 130001 & . albicans CCM 885 & \\
\hline
\end{tabular}

Note: LDPE - low-density poly(ethylene); CuNP - copper nanoparticles.

With use of non-woven polymer material treated by $\mathrm{Cu}$ nanoparticles ability to form biofilms decreased 1.8 times in $E$. coli strains under study, 2.0 times in K. pneumonia strains, 2.2 times for P. aeruginosa strains, 2.4 times for S. aureus, 2.3 times in S. pyogenes strains and 2.6 times in C. albicans strains in comparison with control values (Fig. 5, Table 3, 4).

\section{Discussion}

A large number of scientists have studied the antimicrobial effect of metal nanoparticles on gram-positive and gram-negative bacteria and fungi, including the effect of nanoparticles of copper and its compounds (Oscar et al., 2015; Singh et al., 2015; De Alba-Montero et al., 2017). However, much less attention has been paid to the effect on biofilm formation - the main factor in the antibiotic resistance of microorganisms. 


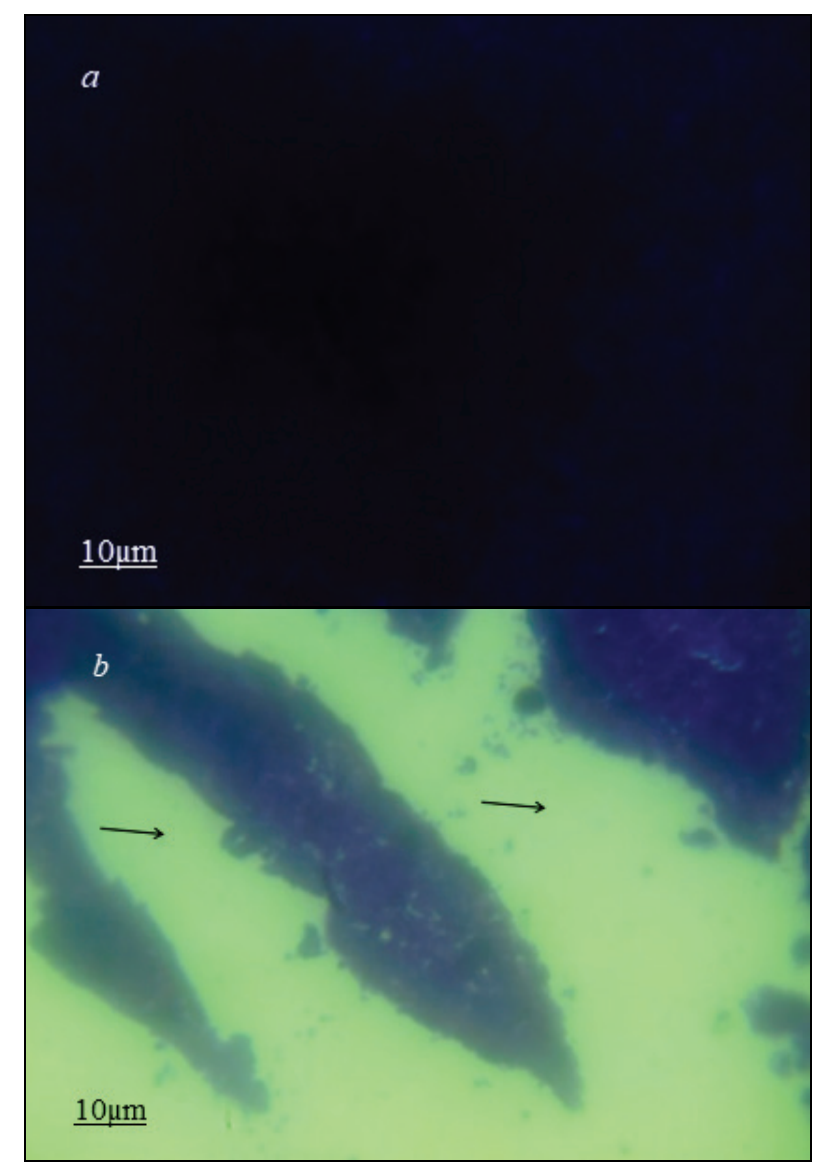

Fig. 5. Daily biofilm: $a$-Staphylococcus aureus (control) and Staphylococcus aureus biofilm; $b$-disorganization of CuNP action; two sets of SEM images

Table 3

$\mathrm{Cu}$ nanoparticles impact on formed daily biofilms of microorganisms

\begin{tabular}{lccc}
\hline \multicolumn{1}{c}{ Microorganism strains } & $\begin{array}{c}\text { Non-woven } \\
\text { polymer material / } \\
\text { CuNP, OD }\end{array}$ & $\begin{array}{c}\text { LDPE/CuNP, } \\
\text { OD }\end{array}$ & $\begin{array}{c}\text { Control, } \\
\text { OD }\end{array}$ \\
\hline $\begin{array}{l}\text { E. coli ATCC 25922 (F50) } \\
\text { = NCDC F 50 }\end{array}$ & $0.86 \pm 0.024 * * *$ & $0.92 \pm 0.017 * * *$ & $1.56 \pm 0.02$ \\
K. pneumonia NCTC 5055 & $0.98 \pm 0.03^{* * *}$ & $1.03 \pm 0.039^{* * *}$ & $1.96 \pm 0.017$ \\
$=$ SS B 5055 & & & \\
$\begin{array}{l}\text { P. aeruginosa ATCC 27853 } \\
\text { = NCDCF-51 }\end{array}$ & $0.99 \pm 0.03^{* * *}$ & $1.34 \pm 0.029^{* * *}$ & $2.16 \pm 0.023$ \\
S. aureus ATCC 25923 & $1.12 \pm 0.028^{* * *}$ & $1.49 \pm 0.021^{* * *}$ & $2.64 \pm 0.016$ \\
NCDC 25923 = F-49 & $1.02 \pm 0.046 * * *$ & $1.38 \pm 0.027 * * *$ & $2.33 \pm 0.018$ \\
S. pyogenes 130001 & $1.14 \pm 0.024^{* * *}$ & $1.52 \pm 0.03^{* * *}$ & $2.96 \pm 0.026$ \\
C. albicans CCM 885 & &
\end{tabular}

Note: LDPE - low-density poly(ethylene); CuNP - copper nanoparticles; DO optical density; $\mathrm{x} \pm \mathrm{SD}, \mathrm{n}=6$, the differences are significant between control and experimental nanocomposites $* * *-\mathrm{P}<0.001$.

Table 4

The density reduction of daily biofilms in comparison with control values

\begin{tabular}{lcc}
\hline \multicolumn{1}{c}{ Microorganism strains } & $\begin{array}{c}\text { LDPE/CuNP, } \\
\text { times }\end{array}$ & $\begin{array}{c}\text { Non-woven polymer } \\
\text { material/CuNP, times }\end{array}$ \\
\hline $\begin{array}{l}\text { E. coli ATCC 25922 (F50) } \\
\text { NCDC F 50 }\end{array}$ & 1.7 & 1.8 \\
$\begin{array}{l}\text { K. pneumonia } \text { NCTC 5055= } \\
\text { SS B 5055 }\end{array}$ & 1.9 & 2.0 \\
P. aeruginosa ATCC 27853 & & \\
NCDCF-51 & 1.6 & 2.2 \\
S. aureus ATCC 25923 & & \\
NCDC 25923 = F-49 & 1.8 & 2.4 \\
S. pyogenes 130001 & 1.7 & 2.3 \\
C. albicans CCM 885 & 1.9 & 2.6 \\
\hline
\end{tabular}

Note: LDPE - low-density poly(ethylene); CuNP - copper nanoparticles.
Theivasanthi \& Alagar (2011) revealed that nanoparticles obtained by electrolysis exhibit more antibacterial activity than nanoparticles obtained by chemical reduction. The antibacterial activity of copper nanoparticles is evaluated using standard microbiological analysis of the zones of inhibition of $E$. coli and B. megaterium. Other authors have investigated the effect of copper oxide nanoparticles on the biofilm formation of $S$. aureus. The results of the studies showed that the inhibition of biofilms decreased with increasing concentration of bulk particles of copper oxide compared to nanoscale copper oxide (Murthy et al., 2011). A study by Agarwala et al. (2014) of the biofilm activity of copper oxide nanoparticles revealed that the higher the concentration of nanoparticles, the greater the inhibition of biofilm formation of $E$. coli and methicillin-resistant $S$. aureus, as well as the fact that copper oxide nanoparticles are effective as an antibacterial material against to uropathogens.

Khan \& Yaqoob (2017) studied the inhibitory influence of copper discs on the growth of E. coli, Klebsiella, Candida and proved the bactericidal and fungicidal properties of copper, and also proposed the use of copper alloys for the manufacture of various surfaces in hospitals to prevent nosocomial infections. Widyńska et al. (2018) studied the effect of 2$15 \mathrm{~nm}$ copper nanoparticles on biofilms and proved that copper nanoparticles reduce the number of the biofilm-forming bacteria $S$. aureus, and also pointed out the possible use of copper nanoparticles to cover surgical instruments and endoprostheses to prevent the formation of biofilms. Ghasemian et al. (2015) proved the antimicrobial effect of glass and steel surfaces coated with copper nanoparticles $(\mathrm{CuNP})$ with an average size of $8 \mathrm{~nm}$ on the inhibition of biofilm formation on the example of Listeria monocytogenes and Pseudomonas aeruginosa.

Some authors (Heliopoulos et al., 2013) used wool fabric with an alginate and copper ions coating as an antimicrobial agent using the example of $E$. coli. Ahire et al. (2016) investigated in their study the influence of copper nanoparticles that were incorporated into nanofibers during the electrospinning of poly-D,llactide(PDLLA) and poly(ethyleneoxide) on biofilm formation. As a result, it was found that the biofilm formation of $P$. aeruginosa and $S$. aureus decreased by $41 \%$ and $50 \%$, respectively, due to copper released from the nanofibers. The authors recommend these nanofibers for the manufacture of dressings.

Our data confirm the antimicrobial effect of CuNP impregnated into polymer matrices on the formation of biofilms. In addition, the disorganization action of nanocomposites against the formed daily biofilms was found. Our study confirms that CuNP can be used to protect nanocomposites from destruction by microorganisms.

\section{Conclusions}

Complex studies of antimicrobial activity of products from low-density polyethylene as well as products from non-woven material (a mixture of woven and polyester fibers) delivered by impregnation with their $\mathrm{Cu}$ nanoparticles was carried out. Antimicrobial activity of $\mathrm{Cu}$ nanoparticles on planktonic forms of microorganisms was found, which prevents formation of dense biofilms by the microorganisms. With the use of nanocomposite strings filled by $\mathrm{Cu}$, the ability of planktonic cells of referent strains of microorganisms to form biofilms was detected to decrease by 1.7 (E. coli) - 12.3 (K. pneumonia) times in the researched strains. With the use of non-woven polymer material treated by $\mathrm{Cu}$ nanoparticles, the ability to form biofilms decreased by 1.8 (E. coli) -21.8 (K. pneumonia) times in the researched strains.

Based on the research carried out, we may conclude that the investigated polymer nanocomposites might be recommended not only as polymer materials with high antimicrobial activity for medical applications, but also for use in devices in various industries. These results can be recommended for use as preventive measures against nosocomial infections.

The authors gratefully acknowledge Z. R. Ulberg, T. G. Guzina, S. M. Dibkova, and L. S. Rezinchenko for the original technique for obtaining copper nanoparticles.

\section{References}

Agarwala, M., Choudhury, B., \& Yadav, R. N. S. (2014). Comparative study of antibiofilm activity of copper oxide and iron oxide nanoparticles against mul- 
tidrug resistant biofilm forming uropathogens. Indian Journal of Microbiology, 54(3), 365-368.

Ahire, J. J., Hattingh, M., Neveling, D. P., \& Dicks, L. M. T. (2016) Copper-containing anti-biofilm nanofiber scaffolds as a wound dressing material. PLoS One, 11(3), e0152755.

Babker, A. M. A, Sotnik, S., \& Lyashenko, V. (2018). Polymeric materials in medicine. Scholars Journal of Applied Medical Sciences, 6(1C), 148-153.

Borkow, G., \& Gabbay, J. (2009). Copper, an ancient remedy returning to fight microbial, fungal and viral infections. Current Chemical Biology, 3(3), 272-278.

DeAlba-Montero, I., Guajardo-Pacheco, J., Morales-Sánchez, E., Araujo-Martínez, R., Loredo-Becerra, G. M., Martínez-Castañón, G.-A., Ruiz, F., \& Compeán Jasso, M. E. (2017). Antimicrobial properties of copper nanoparticles and amino acid chelated copper nanoparticles produced by using a soya extract. Bioinorganic Chemistry and Applications, 2017, 1-6.

Deng, X., Yu Nikiforov, A., Coenye, T., Cools, P., Aziz, G., Morent, R., De Geyter, N., \& Leys, C. (2015). Antimicrobial nano-silver non-woven polyethylene terephthalate fabric via an atmospheric pressure plasma deposition process. Scientific Reports, 5(1), 10138.

Devi, R., Kannan, V., Natarajan, K., Nivas, D., Kannan, K., Chandru, S., \& Antony, A. (2015). The role of microbes in plastic degradation. Environmental Waste Management, 2015, 341-370.

Gaetke, L. M., Chow-Johnson, H. S., \& Chow, C. K. (2014). Copper: Toxicological relevance and mechanisms. Archives of Toxicology, 88(11), 1929-1938.

Ghasemian, E., Naghoni, A., Rahvar, H., Kialha, M., \& Tabaraie, B. (2015). Evaluating the effect of copper nanoparticles in inhibiting Pseudomonas aeruginosa and Listeria monocytogenes biofilm formation. Jundishapur Journal of Microbiology, 8(5), 17430.

Ghori, S. W., Siakeng, R., Rasheed, M., Saba, N., \& Jawaid, M. (2018). The role of advanced polymer materials in aerospace. Sustainable Composites for Aerospace Applications, 2018, 19-34.

Gutiérrez, T. J. (2018). Polymers for food applications: News. Polymers for Food Applications, 2018, 1-4.

Heliopoulos, N. S., Papageorgiou, S. K., Galeou, A., Favvas, E. P., Katsaros, F. K., \& Stamatakis, K. (2013). Effect of copper and copper alginate treatment on wool fabric. Study of textile and antibacterial properties. Surface and Coatings Technology, 235, 24-31.

Jamal, M., Ahmad, W., Andleeb, S., Jalil, F., Imran, M., Nawaz, M. A., Hussain, T., Ali, M., Rafiq, M., \& Kamil, M. A. (2018). Bacterial biofilm and associated infections. Journal of the Chinese Medical Association, 81(1), 7-11.
Khan, M. A., \& Yaqoob, S. (2017). Inhibitory effects of copper on bacterial and fungal growth. International Journal of Medical Research and Review, 5(5), $466-471$.

Khezerlou, A., Alizadeh-Sani, M., Azizi-Lalabadi, M., \& Ehsani, A. (2018). Nanoparticles and their antimicrobial properties against pathogens including bacteria, fungi, parasites and viruses. Microbial Pathogenesis, 123, 505-526.

Koniuszewska, A. G., \& Kaczmar, J. W. (2016). Application of polymer based composite materials in transportation. Progress in Rubber, Plastics and Recycling Technology, 32(1), 1-24.

Krishnan, S. (2015). Biofilm formation on medical devices and infection: Preventive approaches. Biofilm and Materials Science, 2015, 93-108.

Lewis Oscar, F., Mubarak Ali, D., Nithya, C., Priyanka, R., Gopinath, V., Alharbi, N. S., \& Thajuddin, N. (2015). One pot synthesis and anti-biofilm potential of copper nanoparticles (CuNPs) against clinical strains of Pseudomonas aeruginosa. Biofouling, 31(4), 379-391.

Mishina, M., Syrova, A., Abramenko, V., Makarov, V., \& Hopta, O. (2019). Impact of Ag nanoparticles on microorganisms, causative agents of purulentinflammatory processes. Georgian Medical News, 289(4), 139-143.

O’Toole, G., Kaplan, H. B., \& Kolter, R. (2000). Biofilm formation as microbial development. Annual Review of Microbiology, 54(1), 49-79.

Palza, H. (2015). Antimicrobial polymers with metal nanoparticles. International Journal of Molecular Sciences, 16(1), 2099-2116.

Pekhtasheva, E., Neverov, A., \& Zaikov, G. (2012). Biodamage and biodegradation of polymeric materials. Smithers Rapra, Shawbury.

Rokaya, D., Srimaneepong, V., Sapkota, J., Qin, J., Siraleartmukul, K., \& Siriwongrungson, V. (2018). Polymeric materials and films in dentistry: An overview. Journal of Advanced Research, 14, 25-34.

Singh, A., Ahmed, A., Prasad, K. N., Khanduja, S., Singh, S. K., Srivastava, J. K., \& Gajbhiye, N. S. (2015). Antibiofilm and membrane-damaging potential of cuprous oxide nanoparticles against Staphylococcus aureus with reduced susceptibility to Vancomycin. Antimicrobial Agents and Chemotherapy, 59, 11.

Tasneem, U., Yasin, N., \& Qasim, M. (2018). Biofilm producing bacteria: A serious threat to public health in developing countries. Journal of Food Science and Nutrition, 1(2), 25-31.

Theivasanthi, T., \& Alagar, M. (2011). Studies of copper nanoparticles effects on microorganisms. Annals of Biological Research, 2(3), 368-373.

Widyńska, E., Jaworski, S., Strojny, B., \& Zając, A. (2018). Influence of silver and copper nanoparticles on Staphylococcus aureus biofilm formation. Annals of Warsaw University of Life Sciences, 57(2), 193-201. 